\title{
Method Validation for Progesterone Determination in Poly(methyl methacrylate) Nanoparticles Synthesized via Miniemulsion Polymerization
}

\author{
Odinei Fogolari, ${ }^{1}$ Arlindo Cristiano Felippe, ${ }^{2}$ Fernanda Vitória Leimann, ${ }^{3}$ \\ Odinei Hess Gonçalves, ${ }^{3}$ Claudia Sayer, ${ }^{1}$ and Pedro Henrique Hermes De Araújo ${ }^{1}$ \\ ${ }^{1}$ Department of Chemical Engineering and Food Engineering, Federal University of Santa Catarina, \\ 88010970 Florianópolis, SC, Brazil \\ ${ }^{2}$ Federal University of South Frontier (UFFS), Chapecó, SC, Brazil \\ ${ }^{3}$ Post-Graduation Program of Food Technology (PPGTA), Federal University of Technology-Paraná (UTFPR), \\ Campo Mourão, PR, Brazil
}

Correspondence should be addressed to Pedro Henrique Hermes De Araújo; pedro.h.araujo@ufsc.br

Received 7 March 2017; Revised 22 May 2017; Accepted 19 June 2017; Published 1 August 2017

Academic Editor: Ulrich Maschke

Copyright (C) 2017 Odinei Fogolari et al. This is an open access article distributed under the Creative Commons Attribution License, which permits unrestricted use, distribution, and reproduction in any medium, provided the original work is properly cited.

\begin{abstract}
Exogenous progesterone has several applications in human health and in veterinary medicine, especially in fixed-time artificial insemination protocol. Progesterone nanoencapsulation in biocompatible polymers, such as poly(methyl methacrylate) (PMMA), is an alternative to substitute silicone-based release device traditionally used for estrus control. Progesterone concentration inside the nanoparticles must be precisely known; for that reason, a validation methodology must be applied to ensure reliable results, suitable for nanoparticles application. In this work, an UV-Vis spectrophotometric method was validated for the determination of progesterone in PMMA nanoparticles synthesized by miniemulsion polymerization. Chloroform was used as solvent, showing selectivity to the encapsulated drug and the components of the polymeric matrix did not influence progesterone recovery. Detection and quantitation limits (DL and QL) obtained were 0.32 and $0.96 \mathrm{mg} \cdot \mathrm{L}^{-1}$, respectively, and precision tests (between different analysts and equipment) indicated acceptable Relative Standard Deviations ( $\mathrm{RSD}<5 \%$ ). Miniemulsion polymerization reactions were carried out producing two different morphologies: nanospheres (NS) and nanocapsules (NC), with average intensity diameters (Dz) of 150-200 nm and 240-300 nm, respectively. Polymerization gravimetric conversions obtained for both cases were higher than $95 \%$ and encapsulation efficiencies greater than $69 \%$ and $90 \%$ for the nanospheres and nanocapsules, respectively.
\end{abstract}

\section{Introduction}

Progesterone is a steroid hormone with essential functions to reproduction. Drugs with progestogens are used in humans for endometrial protection, dysfunctional bleeding, treatments in pre- or postmenopause, pregnancy maintenance in assisted reproduction treatment, and prevention of premature birth [1]. In veterinary medicine, exogenous progesterone is used especially for cattle in fixed-time artificial insemination protocol, aimed at the synchronization of estrus in females and improvements in fertilization rates. The use of estrus cycle control methods, besides facilitating the management of livestock, allows expanding the use of artificial insemination, accelerating genetic improvement and bringing improvements to the production of meat and milk $[2,3]$.

The incorporation of progesterone in a nanometric matrix can promote prolonged release and be beneficial in various applications [4]. Biopolymer micro- and nanoparticles have been proposed as an alternative to encapsulate progesterone by different techniques, such as glutaraldehyde crosslinking of chitosan or casein dispersed in a nonaqueous phase $[5,6]$ inclusion complex with $\beta$-cyclodextrin or 2 -hydroxypropyl- $\beta$-cyclodextrin [7], miniemulsification/solvent evaporation method $[8,9]$, solvent precipitation $[10,11]$, supercritical $\mathrm{CO}_{2}$ antisolvent expansion of emulsions [12], and water in oil in water double emulsion [13]. 
A technique that stands out in the synthesis of polymeric nanoparticles is miniemulsion polymerization, since it allows several applications for synthesized nanoparticles, including production of high solids and low viscosity latexes, hybrid polymer particles, polymerization in nonaqueous system, step polymerization in aqueous dispersed media, production of low-molecular weight polymers in dispersed media, incorporation of hydrophobic monomers, encapsulation of inorganic solids, and encapsulation of drugs [14]. The encapsulation of hydrophobic compounds by miniemulsion polymerization has been applied for drugs such as indomethacin [15], paclitaxel [16], and tamoxifen [17].

In direct miniemulsion polymerization, the dispersed phase contains the monomer, the costabilizer, and, depending on the application, other compounds of hydrophobic characteristics (e.g., drug to be encapsulated). In order to produce nanodroplets of monomer, a high-shear device is used (sonifier, rotor-stator system as Ultra-Turrax or high-pressure homogenizer) producing a miniemulsion with average droplet sizes between 50 and $500 \mathrm{~nm}$, which is then polymerized [18]. This technique allows the synthesis of solid polymeric particles (nanospheres, NS) and core-shell particles (nanocapsules, NC), with oily core. Drug incorporation and release profile may differ in NS and NC, because they depend on the drug physicochemical properties as well as on the interaction with the encapsulant and the release medium. Hydrophobic drugs such as progesterone tend to be solubilized in the oily nucleus of the NC, increasing the release time.

In a study with amphiphilic $\beta$-cyclodextrin particles dispersed in aqueous medium, Memisoglu-Bilensoy et al. [19] identified that in NS the physicochemical properties of hydrophobic steroid drugs (progesterone, hydrocortisone, and testosterone) play a crucial role in drug loading and release. Authors confirm that the higher the hydrophobicity of the compound, the slower the release process. The release of hydrophobic IR-780 iodide dyes encapsulated in NS and NC prepared with biodegradable polymer no water soluble poly(D,L-lactide) (PLA) or polycaprolactone (PCL) was evaluated by Bazylińska et al. [20]. They observed slower release rates in $\mathrm{NC}$ and confirmed that hydrophobic dye can be more effective when enclosed in the oleic core of a NC than when enclosed only in the polymeric matrix of a NS. Similar results were obtained for indomethacin ethyl ester release in NS and NC of PCL. The presence of the polymer prolonged the ester burst release, while the presence of the oil prolonged the ester sustained release [21].

Particle size is given by the initial droplet dispersion, and both surfactant coverage and surface tension do not significantly change during the process, which makes the nucleation of the droplets the main polymerization mechanism [22]. Degradation phenomena as coalescence and monomeric diffusion (Ostwald ripening) can make the miniemulsion unstable, leading to an increase of droplets size. Nevertheless, this phenomena can be controlled with the use of an emulsifier and costabilizer at appropriate concentrations [14].

The development of polymeric nanoparticles for use in drug delivery should consider the biocompatibility and biodegradability of components. Therefore, the use of biocompatible polymers and solvent-free, natural, and nonionic emulsifiers such as lecithin, in addition of costabilizers based in oils and fatty acids, is preferred for biomedical applications $[9,23-26]$.

PMMA is considered safe for applications in various biomedical products as intraocular lenses, bone cement, and dental material, and it is registered in several cosmetic products [27]. Toxicological studies with the use of PMMA nanoparticles with satisfactory results were obtained by Lekshmi et al. [28] when evaluating in vivo toxicity in albino rats. Authors did not detect any changes in anatomopathological, haematological, and biochemical parameters. PMMA nanoparticles have also demonstrated lower toxicity in vitro assays with human cell cultures (K562 [29], TPH1 e A549 [26]).

Techniques such as Liquid Chromatography [30-32] and Gas Chromatography [33-35] have been used to quantify encapsulated and released progesterone. Few studies have performed progesterone quantification using UV spectrophotometry [4, 36-38]. However, none of them presented the method validation according to international regulations, which is essential to ensure the precision and accuracy of results.

A frequent problem that restricts the use of the spectrophotometric method to compounds quantification is related to low selectivity [30]. However, in matrices in which the formulation components do not interfere significantly in drug absorption spectrum, spectrophotometric methods can provide precision and accuracy, indexes similar to the chromatographic methods, up to a certain concentration range. Maliwal et al. [38] have compared the HPLC method with the UV spectrophotometric method for progesterone determination in commercial formulations (tablets). The methods showed no significant difference and they were considered suitable for routine analyses in tablets.

Since progesterone needs to be extracted from nanoparticles for drug recovery and encapsulation efficiency determinations, a good solvent must be applied to guarantee an accurate result. This implies that polymeric nanoparticle also need to be solubilized. Alcoholic solutions of methanol [36, 38, 39] and propanol [30] often used in progesterone determination protocols are not suitable to the present study, which proposes progesterone encapsulation in PMMA nanoparticles, since these solvents do not favor the dissolution of PMMA polymer chains. Chloroform dissolves PMMA easily and can be an appropriate solvent to progesterone extraction from nanoparticles.

Considering the above, this study aimed at validating a UV spectrophotometric method for progesterone determination in PMMA nanoparticles. Method was validated according to criteria established by the International Council for Harmonisation (specificity, linearity, precision, accuracy, detection limit, quantitation limit, and robustness) and applied to determine the progesterone concentration in PMMA nanoparticles. Nanoparticles parameters such as average diameter and monomer gravimetric conversion were also determined. 


\section{Materials and Methods}

2.1. Materials. Methyl methacrylate (monomer, MMA), 2,2azobisisobutyronitrile (initiator, AIBN), progesterone ( $\mathrm{P} 4$, 99\%), chloroform, and tetrahydrofuran (THF) were purchased from Sigma-Aldrich. Lecithin (Alpha Aesar) was used as surfactant. Crodamol GTCC ${ }^{\circledR}$ (caprylic/capric triglyceride, costabilizer) was purchased from Alpha Química. Deionized water was used in all experiments. All reagents and solvents were analytical grade. AIBN was previously recrystallized in methanol (Sigma-Aldrich), filtered, and vacuum dried.

\subsection{Method Validation for Progesterone Determination in} PMMA Nanoparticles. The validation of spectrophotometric method was performed considering the following parameters: specificity, linearity, precision, accuracy, detection limit (DL), quantitation limit (QL), and robustness, according to the criteria established by the International Council for Harmonisation of Technical Requirements for Pharmaceuticals for Human Use [40]. Two spectrophotometers were used for the method validation: (1) Spectrophotometer Hitachi model U-1900 (spectral bandwidth $4 \mathrm{~nm}$; wavelength accuracy $\pm 0.5 \mathrm{~nm}$; wavelength repeatability $\pm 0.3 \mathrm{~nm}$; photometric accuracy \pm 0.002 Abs; photometric repeatability $0.001 \mathrm{Abs}$ ) and (2) Spectrophotometer Rayleigh, model UV-2601 (spectral bandwidth $2 \mathrm{~nm}$; wavelength accuracy $\pm 0.3 \mathrm{~nm}$; wavelength repeatability $\pm 0.15 \mathrm{~nm}$; photometric accuracy $\pm 0.002 \mathrm{Abs}$; photometric repeatability $0.001 \mathrm{Abs}$ ).

2.2.1. Specificity. The evaluation of the specificity was performed by comparison of the absorption spectra obtained for progesterone with that obtained for nanoparticles (with or without progesterone) solubilized in chloroform. In order to obtain the absorption spectra of the polymer nanoparticles, latex samples were subjected to drying in an oven at $60^{\circ} \mathrm{C}$ until they reached constant weight. Dried samples were then solubilized in chloroform, diluted, and scanned from 200 to $300 \mathrm{~nm}$.

2.2.2. Linearity. For linearity determination, three calibration curves were prepared at different days. For each calibration curve, a standard progesterone solution was prepared in chloroform and subsequently diluted in eight different concentrations, ranging from 2 to $50 \mathrm{mg} \cdot \mathrm{L}^{-1}(n=24)$ and the absorbance measurements were conducted in triplicate for each concentration at $253 \mathrm{~nm}$. Linearity was assessed using linear regression and the quality of model fit was verified by analysis of variance (ANOVA).

2.2.3. Detection Limit (DL) and Quantitation Limit (QL). Detection and quantification limits were obtained based on the slope $(S)$ and standard deviation $(\sigma)$ of the intercept with the axis $Y$ (absorbance) of linearity curves, according to [40]

$$
\begin{aligned}
& \mathrm{LD}=\frac{3.3 \sigma}{S} \\
& \mathrm{LQ}=\frac{10 \sigma}{S} .
\end{aligned}
$$

2.2.4. Precision and Accuracy. Precision was evaluated based on the Relative Standard Deviation (RSD) of a measurement series. This analysis took into consideration repeatability, intermediate precision, and reproducibility [40]. Repeatability was performed by repeating the analytical procedure for 3 concentration levels covering the minimum and maximum concentrations of linearity test. Each concentration was analyzed 7 times, on the same day, by the same analyst and equipment. For intermediate precision, the same procedure was followed, but on different days and by different analysts. Reproducibility was evaluated with the reproduction of the analysis at the intermediate level of concentration in a second laboratory on two different days. Similarly, the accuracy was evaluated based on the Recovery Index $(\operatorname{Rec},(2))$, in the above described analysis, where $[\mathrm{P} 4]_{\text {experimental }}\left(\mathrm{mg} \cdot \mathrm{L}^{-1}\right)$ represents the concentration detected during the analysis at $253 \mathrm{~nm}$ and $[\mathrm{P} 4]_{\text {standard }}$ represents the theoretical concentration of the evaluated dilution.

$$
\operatorname{Rec}=\frac{[\mathrm{P} 4]_{\text {experimental }}}{[\mathrm{P} 4]_{\text {standard }}} \times 100 .
$$

2.2.5. Robustness. Robustness evaluates the ability of the analytical procedure to remain unchanged when subjected to small variations in process parameters. Thus, two brands of the solvent (chloroform, analytical grade) were evaluated to verify a possible interference on P4 quantification. A standard progesterone solution of $520 \mathrm{mg} \cdot \mathrm{L}^{-1}$ was prepared. Then, aliquots of $250 \mu \mathrm{L}$ of this solution were diluted to $5 \mathrm{~mL}$ of each brand of chloroform ("A" and "B"), resulting in a concentration of $26 \mathrm{mg} \cdot \mathrm{L}^{-1}$. Finally, samples were analyzed in 5 replicates at $253 \mathrm{~nm}$.

2.3. PMMA Nanoparticles Synthesis for Progesterone Encapsulation. PMMA nanoparticles were produced by the miniemulsion polymerization technique and the formulations were defined according to previous studies conducted in the research group in the synthesis of biocompatible nanoparticles for drug delivery [23-26]. Formulations used in particles synthesis are presented in Table 1 for nanospheres (NS) and nanocapsules (NC). Considering that MMA monomer presents certain solubility in water $\left(150 \mathrm{mmol} \cdot \mathrm{L}^{-1}\right)$, a hydrophobic initiator (AIBN) was used to prevent secondary nucleation and the formation of pure PMMA particles in the aqueous phase [41].

The organic phase of the miniemulsion was prepared with MMA, lecithin, Crodamol GTCC, AIBN, and drug (P4) when it was specified. These components were homogenized and then mixed during 40 minutes with water, in order to form a macroemulsion. Then, the macroemulsion was subjected to the process of droplet size reduction by sonication (Fisher Scientific, Sonic Dismembrator Model 500, $400 \mathrm{~W}$ ) for 4 minutes at $60 \%$ amplitude (10 s pulse on and $5 \mathrm{~s}$ pulse off). The miniemulsion prepared was equally divided into glass test tubes, which were filled with gaseous nitrogen to remove oxygen from the head space. Finally, the test tubes were closed and immersed in a thermostatic bath at $70^{\circ} \mathrm{C}$ to start the polymerization reaction. Each test tube was removed from 
TABLE 1: Standard miniemulsion formulation for progesterone encapsulation in PMMA nanospheres (NS) or in PMMA nanocapsules (NC).

\begin{tabular}{|c|c|c|c|c|c|c|}
\hline Formulation & Water $(\%)$ & AIBN $(\%)$ & Lecithin (\%) & Crodamol GTCC (\%) & MMA (\%) & $\mathrm{P} 4\left(\mathrm{mg}_{\mathrm{P} 4} \cdot \mathrm{g}_{\text {latex }}{ }^{-1}\right)$ \\
\hline NS & 79.5 & 0.200 & 0.300 & 2.00 & 18.0 & - \\
\hline NS P4 $1 \mathrm{mg}$ & 79.5 & 0.200 & 0.300 & 2.00 & 18.0 & 1 \\
\hline NS P4 2 mg & 79.5 & 0.200 & 0.300 & 2.00 & 18.0 & 2 \\
\hline NS P4 $20 \mathrm{mg}$ & 79.5 & 0.200 & 0.300 & 2.00 & 18.0 & 20 \\
\hline $\mathrm{NC}$ & 79.5 & 0.200 & 0.300 & 10.0 & 10.0 & - \\
\hline NC P4 $20 \mathrm{mg}$ & 79.5 & 0.200 & 0.300 & 10.0 & 10.0 & 20 \\
\hline
\end{tabular}

the bath at a specified time interval and cooled to obtain conversion kinetics and size diameter results.

2.4. Nanoparticles Characterization. Throughout the polymerization reactions, samples were withdrawn to evaluate nanoparticles average diameter $(\mathrm{Dz})$ and diameter polydispersity index (PDI), which were determined by Dinamic Light Scattering using a Zetasizer equipment (Nano Series, Malvern Instruments). Prior to reading, samples were diluted approximately at 1:20(v/v) with previously prepared MMA saturated water.

The morphological characterization of polymeric nanoparticles was performed by Transmission Electron Microscopy (TEM, JEOL model JEM 1011 at $100 \mathrm{kV}$ ). For this analysis, drops of the diluted samples $(0.05 \%, \mathrm{v} / \mathrm{v})$ were placed on a 300-mesh Formvar/carbon copper grid (Electron Microscopy Science). After drying, samples were sputter-coated with a thin carbon film to avoid degradation of the PMMA under the electron beam.

Methyl methacrylate gravimetric conversion $\left(X_{\mathrm{g}}\right)$ was determined as described by Bernardy et al. (2010) [25]. Thus, latex samples ( $2 \mathrm{~g}$ ) were taken at different time intervals from the reaction media and transferred to previously weighted aluminum capsules containing $0.2 \mathrm{~g}$ of $1 \mathrm{wt}$. $\%$ hydroquinone aqueous. After that, capsules were dried at $60^{\circ} \mathrm{C}$ until reaching constant weight. Conversion was determined as the ratio between experimental and theoretical polymer contents. The fraction of nonvolatile components (emulsifier, costabilizers, hydroquinone, and progesterone) was deducted from the polymer fraction.

The residual monomer content was determined in latex samples at the end of the polymerization reaction (280 min). Analyses were performed by Headspace Gas Chromatography (GC 2010AF Shimadzu) equipped with a Flame Ionization Detector (FID) using the total evaporation technique of the volatile fraction from the sample. A calibration curve was prepared with standard samples containing the monomer to be measured, analyzed in triplicate.

PMMA molecular weight distributions were determined by Gel Permeation Chromatography (GPC) using HighPerformance Liquid Chromatography (HPLC, Shimadzu, model LC-20A), with three columns Shimadzu Shim Pack GPC 800 Series $300 \times 8 \mathrm{~mm}$ (GPC 801, GPC 804 e GPC 807), refractive index detector (model RID-10A) and autosampler (model SIL-20A). Latex samples $(0.02 \mathrm{~g})$ were initially solubilized in tetrahydrofuran (THF, $4 \mathrm{~mL})$, filtered $(0.45 \mu \mathrm{m})$, and finally analyzed. THF was used as mobile phase at a flow rate of $1 \mathrm{~mL} \cdot \mathrm{min}^{-1}$ and $35^{\circ} \mathrm{C}$. The polymer molecular weights were determined from a calibration curve produced with polystyrene standards with molecular weights between $580 \mathrm{~g} \cdot \mathrm{mol}^{-1}$ and $9.835 \times 10^{6} \mathrm{~g} \cdot \mathrm{mol}^{-1}$.

2.5. Progesterone Recovery Yield (RY) and Encapsulation Efficiency (EE) in PMMA Nanoparticles. In order to evaluate possible interferences of the components of the polymeric nanoparticles in drug recovery yield (RY), PMMA nanoparticles were prepared, according to Table 1, with progesterone concentrations of 1,2 , and $20 \mathrm{mg}_{\mathrm{P} 4} \cdot \mathrm{g}_{\text {latex }}{ }^{-1}$. With the purpose of determining RY, latex samples $(1.5 \mathrm{~g})$ were dried at $60^{\circ} \mathrm{C}$ and solubilized in $10 \mathrm{~mL}$ of chloroform. Aliquots were diluted to obtain absorbance values between 0.3 and 1.0 at $253 \mathrm{~nm}$. Each formulation was analyzed in triplicate and the RY was calculated with (3), where $C_{\text {rec }}\left(\mathrm{mg} \cdot \mathrm{mL}^{-1}\right)$ is the concentration of recovered progesterone after nanoparticles synthesis and $C_{\text {theoretical }}\left(\mathrm{mg} \cdot \mathrm{mL}^{-1}\right)$ is the progesterone concentration added to the nanoparticles synthesis formulation.

For determining the encapsulation efficiency (EE), polymer particles were separated from the aqueous phase by centrifugation at $13.528 \times \mathrm{g}$ for $45 \mathrm{~min}$. The precipitate was dried at $60^{\circ} \mathrm{C}$, dissolved in $10 \mathrm{~mL}$ of chloroform, diluted, and filtered (PTFE, $0.2 \mu \mathrm{m}$ ) and the absorbance was determined at $253 \mathrm{~nm}$. Encapsulation efficiency (EE) was then obtained according to (4), where $M_{\text {rec }}$ is the mass of recovered progesterone in precipitate, $M_{\mathrm{lt}}$ is latex mass, and $F_{\mathrm{P} 4}$ is the progesterone fraction in the latex. Each formulation was measured in triplicate and latex samples without progesterone were subjected to the same treatment and served as reference (blank sample) in spectrophotometric readings.

$$
\begin{aligned}
\mathrm{RY} & =\frac{C_{\text {rec }}}{C_{\text {theoretical }}} \times 100 \\
\mathrm{EE}(\%) & =\frac{M_{\mathrm{rec}}}{F_{\mathrm{P} 4} \times M_{\mathrm{lt}}} \times 100 .
\end{aligned}
$$

\section{Results and Discussion}

\subsection{Method Validation for Progesterone Determination in PMMA Nanoparticles}

3.1.1. Specificity. In quantification tests, specificity results should ensure that the procedure is not affected by the presence of impurities or excipients [42]. Figure 1 presents the absorption spectra of pure progesterone (P4) and of the 


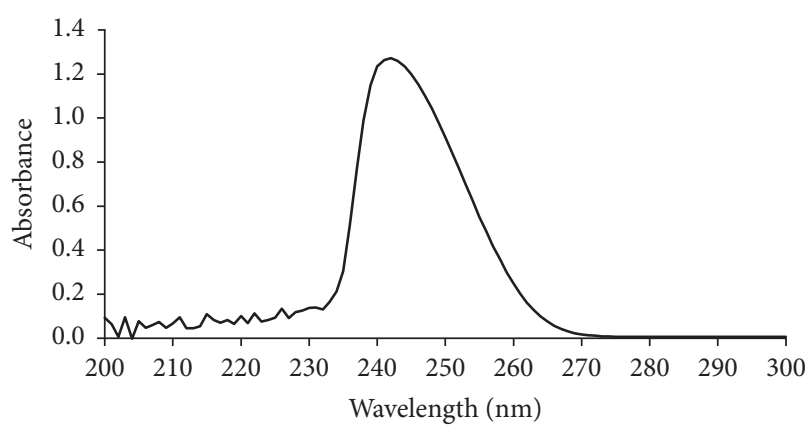

$-\mathrm{P} 4$

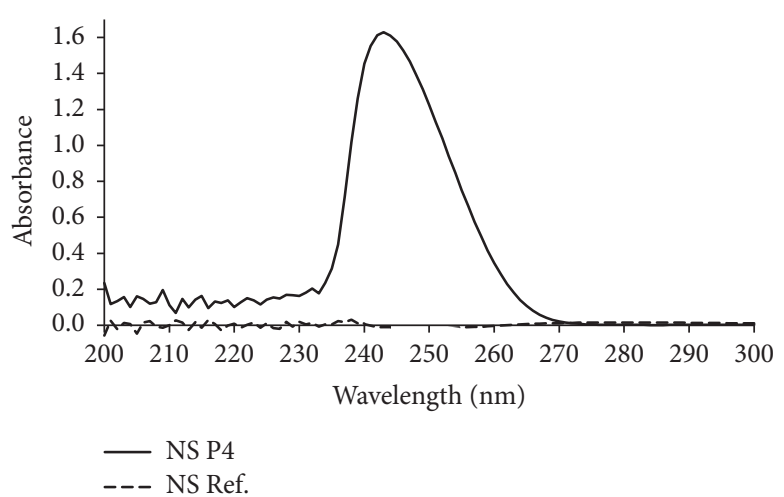

(b)

FIGURE 1: UV absorption spectra of (a) pure P4 and (b) P4-loaded NS (20 mg. $\mathrm{g}^{-1}$ ) and NS reference (no P4 added).

PMMA nanoparticles. In the ultraviolet region, progesterone presents only one absorption peak located between 230 and $270 \mathrm{~nm}$. The maximum absorption is between 241 and $243 \mathrm{~nm}$ (Figure 1(a)); however, the cut off of the solvent is $245 \mathrm{~nm}$, making it infeasible to quantify the analyte at wavelengths below this value. Therefore, the methodology was validated using absorbance at $253 \mathrm{~nm}$, where drug absorption is high and the interference of the solvent is considerably reduced.

Progestogen free nanospheres (blank sample) when solubilized in chloroform have absorbance near to zero in the measured spectrum region (Figure $1(\mathrm{~b})$ ) and nanocapsules presented the same behavior. Thus, it is demonstrated that the method is selective to the progesterone among the components of PMMA nanoparticles (polymer, emulsifier, and costabilizer) at $253 \mathrm{~nm}$.

3.1.2. Linearity, Detection Limit (DL), and Quantitation Limit $(Q L)$. The resulting standard curve "Abs $=0.0277 * \mathrm{C}+$ 0.0035 " showed adjusted coefficient of determination $\left(R_{\text {adj }}^{2}\right)$ of 0.997 , indicating high proportionality index between concentration and absorbance in the range of 2 and $50 \mathrm{mg} \cdot \mathrm{L}^{-1}$. The analysis of variance (ANOVA, unilateral test) of the results confirmed that the linear regression model was significant (for $p<0.05$ ), presenting no lack of fit.

$\mathrm{DL}$ and QL estimated by (1) were $0.32 \mathrm{e} 0.96 \mathrm{mg} \cdot \mathrm{L}^{-1}$, respectively, showing that the method is able to detect and quantify small concentrations of the P4 in the sample. Considering an optimal working range between 10 and $40 \mathrm{mg} \cdot \mathrm{L}^{-1}$, QL corresponds to $10 \%$ of the less value of this range being therefore acceptable for the method.

3.1.3. Precision and Accuracy. Results of the repeatability and intermediate precision are shown in Table 2, which contains analyses at 3 concentration levels, performed by different analysts in different days. In Table 3 calculated and critical $t$ values obtained through Student's $t$-test are presented.

The results of RSD were less than $5 \%$ in the evaluation of intermediate precision and repeatability, including the maximum and minimum concentrations evaluated.

In all possible comparisons, the means found for the maximum and intermediate concentration showed no difference to the confidence level of $95 \%$. For the minimum concentration the comparison between means of "Day 1/Analyst A versus Day 2/Analyst A" and "Day 1/Analyst A versus Day 2/Analyst B" showed statistical differences for the aforementioned confidence level. However, variations are expected and acceptable for concentrations near to the limit of quantification.

The results obtained for reproducibility in a second laboratory (Lab. B) are shown in Table 4. The comparison of interlaboratory means, performed by Student's $t$-test is shown in Table 5.

Means have RSD less than $5 \%$, which is an acceptable value. According to the data, there is no statistical difference at a confidence level of $95 \%$ for all possible comparisons. With respect to the accuracy, one may observe that the difference between theoretical and recovered values, for intermediate and maximum concentrations, was less than $7 \%$ (Tables 2 and 4). Therefore, in general, the recovery data were satisfactory and compatible with the proposed method.

3.1.4. Robustness. The robustness was carried out considering the possibility of acquiring solvents of different trademarks. Table 6 shows the comparison results of the analyses conducted with two different solvents suppliers.

The results showed that the use of analytical grade solvents from different suppliers did not interfere in the analysis. The means showed no statistical difference at a significance level of 0.05 for Student's $t$-test. Also, no statistical difference regarding the standard concentration of $26.0 \mathrm{mg} \cdot \mathrm{L}^{-1}$ was detected.

3.2. PMMA Nanoparticles Characterization and Progesterone Determination. The proportion of $1: 9$ and $1: 1$ between MMA : Crodamol favored, respectively, the formation of particles with nanospheres (NS) and nanocapsules (NC) morphology, as it was verified by other authors [23, 25, 43]. The images presented in Figure 2 confirm these morphologies. In Figure 2(a) spherical solid particles with lower size dispersion can be observed. On the other hand, in Figure 2(b) one may observe that particles formed a core composed by Crodamol and an outer layer composed by PMMA, characteristics of 
TABLE 2: Repeatability evaluation and intermediate precision results.

\begin{tabular}{|c|c|c|c|c|c|c|}
\hline$C_{\text {Standard }}\left(\mathrm{mg} \cdot \mathrm{L}^{-1}\right)$ & Calculated concentration $\left(\mathrm{mg} \cdot \mathrm{L}^{-1}\right)^{1}$ & $\operatorname{RSD}(\%)^{2}$ & $\operatorname{Rec}(\%)^{3}$ & Calculated concentration $\left(\mathrm{mg} \cdot \mathrm{L}^{-1}\right)$ & RSD (\%) & $\operatorname{Rec}(\%)$ \\
\hline & \multicolumn{3}{|c|}{ Day 1/Analyst A } & \multicolumn{3}{|c|}{ Day 2/Analyst A } \\
\hline 52.0 & $53.4 \pm 0.6$ & 1.2 & 102.6 & $52.6 \pm 0.7$ & 1.4 & 101.2 \\
\hline 26.0 & $27.1 \pm 0.2$ & 0.8 & 104.3 & $27.2 \pm 0.6$ & 2.1 & 104.7 \\
\hline \multirow[t]{2}{*}{2.1} & $2.3 \pm 0.1$ & 4.6 & 109.4 & $2.4 \pm 0.1$ & 4.8 & 116.1 \\
\hline & \multicolumn{3}{|c|}{ Day 1 /Analyst B } & \multicolumn{3}{|l|}{ Day 2/Analyst B } \\
\hline 52.0 & $53.3 \pm 1.3$ & 2.4 & 102.5 & $52.8 \pm 1.0$ & 1.8 & 101.5 \\
\hline 26.0 & $27.7 \pm 0.8$ & 2.9 & 106.6 & $27.5 \pm 0.5$ & 1.9 & 105.9 \\
\hline 2.1 & $2.3 \pm 0.1$ & 3.7 & 111.4 & $2.4 \pm 0.1$ & 2.7 & 114.8 \\
\hline
\end{tabular}

${ }^{1}$ Mean \pm standard deviation $(n=7) ;{ }^{2}$ Relative Standard Deviation; ${ }^{3}$ recovery.

TABLE 3: Student's $t$-test to the mean data in the evaluation of the repeatability and intermediate precision.

\begin{tabular}{|c|c|c|c|c|c|}
\hline \multirow{2}{*}{$C_{\text {Standard }}\left(\mathrm{mg} \cdot \mathrm{L}^{-1}\right)$} & \multirow{2}{*}{ Conditions } & \multicolumn{3}{|c|}{$t_{\text {calculated }}$} & \multirow{2}{*}{$t_{\text {critical }}{ }^{*}$} \\
\hline & & Day 2/Analyst A & Day $1 /$ Analyst B & Day 2/Analyst B & \\
\hline \multirow{3}{*}{52.0} & Day $1 /$ Analyst A & 2.060 & 0.151 & 1.328 & 2.178 \\
\hline & Day 2/Analyst A & - & 1.187 & 0.376 & 2.178 \\
\hline & Day 1/Analyst B & - & - & 0.812 & 2.178 \\
\hline \multirow{3}{*}{26.0} & Day $1 /$ Analyst A & 0.461 & 1.951 & 2.006 & 2.178 \\
\hline & Day 2/Analyst A & - & 1.345 & 1.068 & 2.178 \\
\hline & Day $1 /$ Analyst B & - & 一 & 0.528 & 2.178 \\
\hline \multirow{3}{*}{2.1} & Day 1/Analyst A & 2.368 & 0.812 & 2.449 & 2.178 \\
\hline & Day 2/Analyst A & - & 1.803 & 0.514 & 2.178 \\
\hline & Day $1 /$ Analyst $B$ & - & - & 1.783 & 2.178 \\
\hline
\end{tabular}

${ }^{*} t$ value for bilateral test $(p<0.05$; degrees of freedom $=12)$.

TABLE 4: Results of the reproducibility of the method.

\begin{tabular}{lcccc}
\hline$C_{\text {Standard }}\left(\mathrm{mg} \cdot \mathrm{L}^{-1}\right)$ & Conditions & Mean $(\mathrm{mg} / \mathrm{L})^{*}$ & RSD $(\%)$ & Rec $(\%)$ \\
\hline \multirow{2}{*}{26.0} & Day 1/Lab. B & $26.9 \pm 0.8$ & 3.1 & 103.3 \\
& Day 2/Lab. B & $27.2 \pm 1.2$ & 4.5 & 104.6 \\
\hline
\end{tabular}

${ }^{*}$ Mean \pm standard deviation $(n=7)$.

TABLE 5: Student's $t$-test to the mean data in the evaluation of the reproducibility.

\begin{tabular}{lcccc}
\hline & & $t_{\text {calculated }}$ & \\
& Day 2/Lab. A & Day 1/Lab. B & Day 2/Lab. B & $t_{\text {critical }}{ }^{*}$ \\
\hline Day 1/Lab. A & 0.461 & 0.758 & 0.335 & 2.178 \\
Day 2/Lab. A & - & 0.922 & 0.119 & 2.178 \\
Day 1/Lab. B & - & - & 0.697 & 2.178 \\
\hline
\end{tabular}

${ }^{*} t$ value for bilateral test $(p<0.05$; degrees of freedom $=12)$.

nanocapsules. NCs (Figure 2(b)) presented higher particles sizes dispersion, confirming data obtained by DLS.

Polymerization reactions were carried out with the formulations shown in Table 1, varying only the concentration of progesterone. Table 7 shows the concentration of progesterone based on the mass added to the formulation, the concentration obtained by spectrophotometric analysis in recovery yield (RY), and the encapsulation efficiency (EE).

Recovery yield (RY) determined by (3) was between 94 and $106 \%$, showing that the method is robust with respect to formulation components, which did not influence the quantification of the drug. Encapsulation efficiency (EE) was 


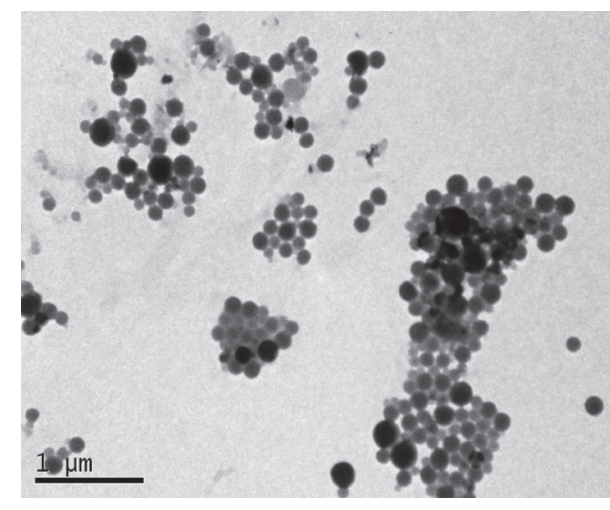

(a)

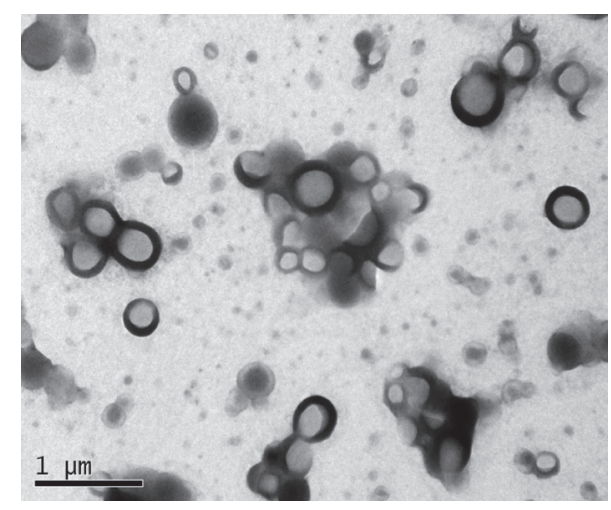

(b)

FIGURE 2: TEM micrographs of PMMA (a) nanospheres and (b) nanocapsules, both using $1 \mathrm{mg}_{\mathrm{P} 4} \cdot \mathrm{g}_{\text {latex }}{ }^{-1}$.

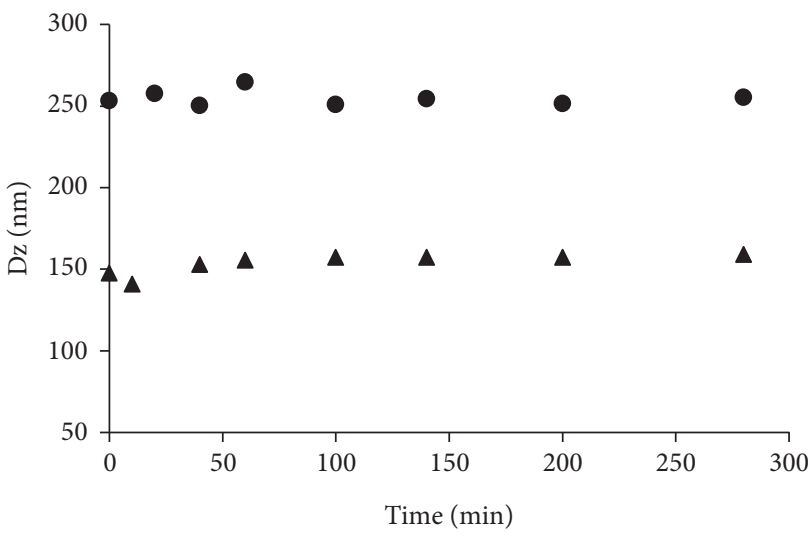

- NC Ref.

- NS Ref

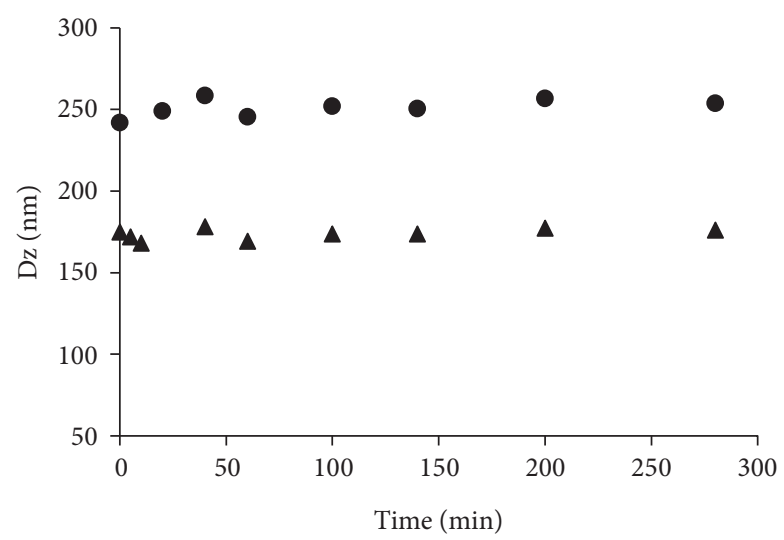

- NC P4

- NS P4

(a)

(b)

FIGURE 3: Average intensity diameter (Dz) of nanoparticles during miniemulsion polymerization for the formation of PMMA blank nanoparticles (Ref.) (a) and with progesterone (P4; $1 \mathrm{mg}_{\mathrm{P} 4} \cdot \mathrm{g}_{\text {latex }}{ }^{-1}$ ) (b). NC (nanocapsules) and NS (nanospheres).

TABLE 6: Robustness results for analyses with different brands of chloroform.

\begin{tabular}{lcc}
\hline Sample & Chloroform A & Chloroform B \\
\hline Mean $\left(\mathrm{mg} \cdot \mathrm{L}^{-1}\right)^{*}$ & $26.6 \pm 0.8^{\mathrm{a}}$ & $25.7 \pm 0.6^{\mathrm{a}}$ \\
RSD (\%) & 3.2 & 2.5 \\
$\operatorname{Rec}(\%)$ & 102.3 & 98.8 \\
\hline
\end{tabular}

${ }^{*}$ Mean \pm standard deviation $(n=5)$ for standard $26.0 \mathrm{mg} / \mathrm{L}$. ${ }^{a}$ There is no significant difference between the means by Student's $t$-test $(p<0,05)$.

high when low P4 concentrations were used, but it was decreased for the highest $\mathrm{P} 4$ concentration used meaning that there is a limit in the amount of P4 that could be incorporated in the nanoparticles. In fact, the reduction of the $\mathrm{EE}$ for the concentration of $20 \mathrm{mg} \cdot \mathrm{g}^{-1}$ was expected, because it is a relatively high charge for the formulation (about $10 \%$ solids fraction). It was found that nanocapsules have higher encapsulation efficiency than nanospheres, probably due to the higher solubility of progesterone in Crodamol than in PMMA.

Polymerization reactions with the proposed formulations (Table 1) were evaluated with $1 \mathrm{mg}_{\mathrm{P} 4} \cdot \mathrm{g}_{\text {latex }}{ }^{-1}$. The average intensity diameter results $(\mathrm{Dz})$ of the nanodroplets/nanoparticles throughout the polymerization reactions are shown in Figure 3.

PMMA nanocapsules (NC) presented average diameter between 240 and $290 \mathrm{~nm}$, and polydispersity indexes (PDI) between 0.20 and 0.25 . On the other hand, PMMA nanosphere (NS) presented lower $\mathrm{Dz}$ results, between 150 and $200 \mathrm{~nm}$, as well as a monodisperse size distribution, with PDI below 0.13. Figures 3(a) and 3(b) show that the presence of progesterone did not considerably change particles diameter, reflecting the stability of the miniemulsion even in the presence of progesterone. The ratio between the final particle diameter (250 min of reaction) and the nanodroplets diameter (beginning of the reaction) was 1.05 for NC and 1.01 for NS. Therefore, the increase in the average size was 
TABLE 7: Added and calculated P4 concentration and encapsulation efficiency (EE) in PMMA nanoparticles.

\begin{tabular}{lccr}
\hline Formulation $^{1}$ & ${\text { P4 added }\left(\mathrm{mg} \cdot \mathrm{g}^{-1}\right)}$ & ${\text { P4 calculated }\left(\mathrm{mg} \cdot \mathrm{g}^{-1}\right)^{2}}$ & EE $(\%)$ \\
\hline NS 1 mg P4 & 1.09 & $1.16 \pm 0.27$ & $94 \pm 1$ \\
NS 2 mg P4 & 1.99 & $2.05 \pm 0.14$ & $100 \pm 3$ \\
NS 20 mg P4 & 20.36 & $19.21 \pm 0.36$ & $69 \pm 3$ \\
NC 20 mg P4 & 19.99 & $20.20 \pm 1.71$ & $90 \pm 1$ \\
\hline
\end{tabular}

${ }^{1}$ Nanospheres (NS) and nanocapsules (NC) formulations prepared as shown in Table 1, except for the concentration of progesterone (P4); ${ }^{2} \mathrm{P} 4$ concentration calculated using the validated method.

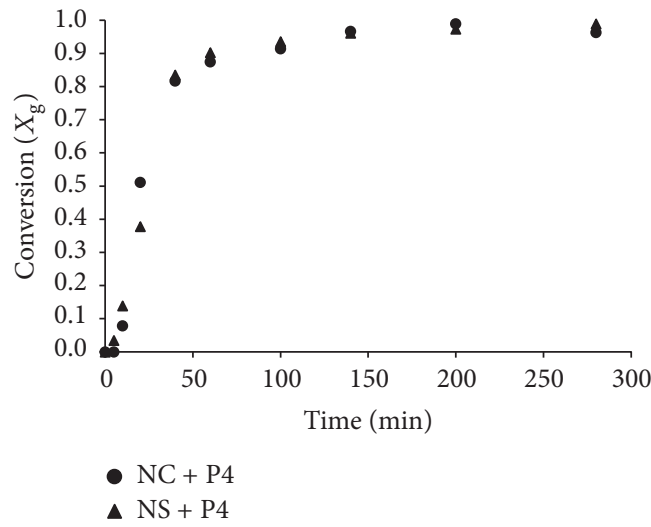

(a)

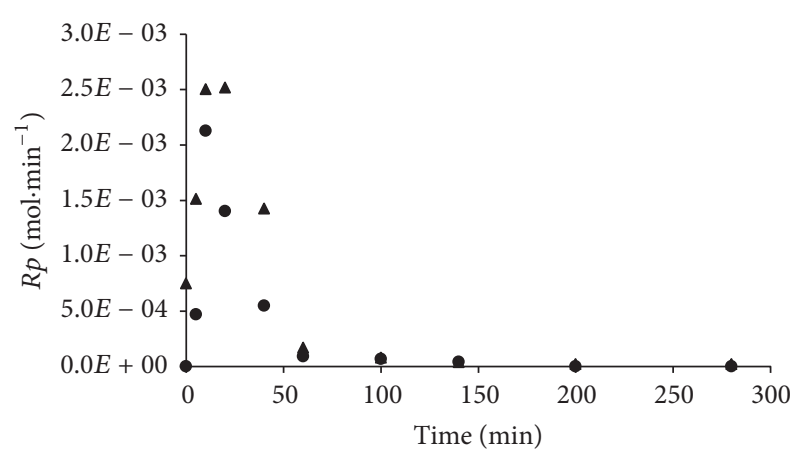

- $\mathrm{NC}+\mathrm{P} 4$

- $\mathrm{NS}+\mathrm{P} 4$

FIGURE 4: (a) Conversion and (b) reaction rate (Rp) during miniemulsion polymerization for the formation of PMMA NC (nanocapsules) and NS (nanospheres) using $1 \mathrm{mg}_{\mathrm{P} 4} \cdot \mathrm{g}_{\text {latex }}{ }^{-1}$.

TABLE 8: Residual monomer content obtained by gas chromatography at the end of the reactions $(t=280 \mathrm{~min})$.

\begin{tabular}{lcc}
\hline Formulation & P4 $\left({\left.\mathrm{mg} \cdot \mathrm{g}^{-1}\right)}^{-}\right.$ & Residual monomer $(\%)$ \\
\hline NS & - & 0.60 \\
NS & 20 & 0.20 \\
NC & - & 0.10 \\
NC & 20 & 0.20 \\
\hline
\end{tabular}

negligible, indicating the absence of degradation phenomena such as coalescence or diffusional degradation. Particle size stability also suggests that nucleation of the droplets was the main reaction mechanism of polymerization [22].

In Figure 4 the evolution of the gravimetric conversion (a) and the reaction rate (b) are presented. Residual monomer results are shown in Table 8 and in Figure 5 molar masses distributions are presented.

The behavior of the polymerization kinetics for the formation of NC and NS with $1 \mathrm{mg}_{\mathrm{P} 4} \cdot \mathrm{g}_{\text {latex }}{ }^{-1}$ was similar and, after $280 \mathrm{~min}$, the reaction reached a conversion up to $97 \%$. The reduction in the reaction rate $(\mathrm{Rp})$ for $\mathrm{NC}$ observed in Figure 4(b) did not damage the polymer conversion. The reduction in the $\mathrm{Rp}$ is a consequence of the lower number of particles in the system for NC (higher Dz; see Figure 3) causing an increase in the number of radicals/particle proportion and, consequently, in the rate of radical termination. The presence of residual monomer in the latex samples is undesirable, because it may increase toxicity. Data indicated that the monomer content in the samples is low, less than $0.6 \%$. These results agree with those obtained by Feuser et al. [44], which did not detect residual monomer in PMMA samples synthesized by miniemulsion polymerization, with a similar formulation.

In addition to changing the reaction rate, the small particle size can increase the molar mass of the polymer. Systems with higher number of particles and smaller Dp have a lower ratio of number of radical/particles, allowing the growth of the polymer chain and the increase of the molar mass. This can be verified on the weight average molar mass $(M w)$ of the nanospheres, whose value was $510 \mathrm{kDa}$, while for nanocapsules it was close to $440 \mathrm{kDa}$. These results are in accordance with Tiarks et al. [41] who observed increase of Dp and molar mass reduction with increasing stabilizer concentration in PMMA nanocapsules. Samples with progesterone had average weight of $445 \mathrm{kDa}$ and $380 \mathrm{kDa}$, respectively, for nanospheres and nanocapsules. Despite this reduction, the analysis of the molar mass distribution, shown in Figure 5, indicated that the drug effect is insignificant in this parameter.

\section{Conclusions}

The validated UV spectrophotometric method was selective, precise, accurate, and robust enough for the determination of progesterone in polymeric nanoparticles of PMMA. Relative Standard Deviation was lower than $5 \%$ in all experimental 

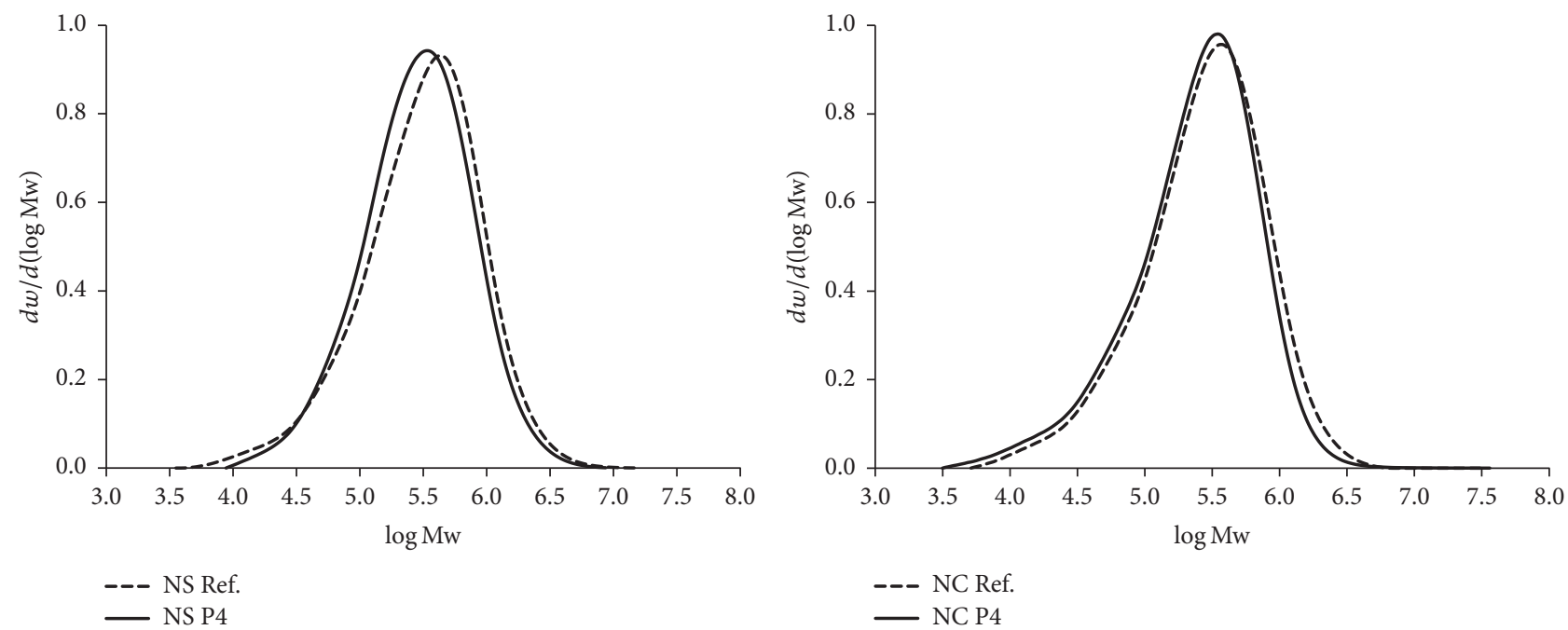

FIguRE 5: Distribution of the molar masses in PMMA nanoparticles reference (Ref.; drug free) and with $20 \mathrm{mg}_{\mathrm{P} 4} \cdot \mathrm{g}_{\text {latex }}{ }^{-1}$ (NS: nanospheres; NC: nanocapsules).

conditions evaluated. With respect to the accuracy, the maximum percentage difference obtained between progesterone added and recovered was 7\% for intermediate working concentration $\left(26 \mathrm{mg} \cdot \mathrm{L}^{-1}\right)$. The methodology was applied to determine encapsulation efficiency of progesterone in PMMA nanocapsules and nanospheres. The tests performed with nanoparticles showed satisfactory results, indicating that the polymer matrix and their components, when solubilized in chloroform, did not interfere in the quantification of the progesterone. The biocompatible formulations used in the synthesis of PMMA nanoparticles demonstrated stability and potential for the incorporation of progesterone. Moreover, the presence of progesterone did not cause significant changes in parameters such as particle diameter, monomer conversion, and molar mass.

\section{Conflicts of Interest}

The authors declare that there are no conflicts of interest regarding the publication of this paper.

\section{References}

[1] X. Ruan and A. O. Mueck, "Systemic progesterone therapy Oral, vaginal, injections and even transdermal?" Maturitas, vol. 79, no. 3, pp. 248-255, 2014.

[2] P. S. Baruselli, E. L. Reis, M. O. Marques, L. F. Nasser, and G. A. Bó, "The use of hormonal treatments to improve reproductive performance of anestrous beef cattle in tropical climates," Animal Reproduction Science, vol. 82-83, pp. 479-486, 2004.

[3] R. Islam, "Synchronization of Estrus in Cattle: a review," Veterinary World, vol. 4, no. 3, pp. 136-141, 2009.

[4] J. E. Oliveira, E. S. Medeiros, L. Cardozo et al., "Development of poly(lactic acid) nanostructured membranes for the controlled delivery of progesterone to livestock animals," Materials Science and Engineering C, vol. 33, no. 2, pp. 844-849, 2013.
[5] S. R. Jameela, T. V. Kumary, A. V. Lal, and A. Jayakrishnan, "Progesterone-loaded chitosan microspheres: A long acting biodegradable controlled delivery system," Journal of Controlled Release, vol. 52, no. 1-2, pp. 17-24, 1998.

[6] M. S. Latha, A. V. Lal, T. V. Kumary, R. Sreekumar, and A. Jayakrishnan, "Progesterone release from glutaraldehyde crosslinked casein microspheres: in vitro studies and in vivo response in rabbits," Contraception, vol. 61, no. 5, pp. 329-334, 2000.

[7] E. Lemos-Senna, D. Wouessidjewe, S. Lesieur, and D. Duchêne, "Preparation of amphiphilic cyclodextrin nanospheres using the emulsification solvent evaporation method. Influence of the surfactant on preparation and hydrophobic drug loading," International Journal of Pharmaceutics, vol. 170, no. 1, pp. 119$128,1998$.

[8] J. Matsumoto, Y. Nakada, K. Sakurai, T. Nakamura, and Y. Takahashi, "Preparation of nanoparticles consisted of poly $(\mathrm{L}-$ lactide)-poly(ethylene glycol)-poly(L-lactide) and their evaluation in vitro," International Journal of Pharmaceutics, vol. 185, no. 1, pp. 93-101, 1999.

[9] F. V. Leimann, M. H. Biz, K. C. Kaufmann et al., "Characterization of progesterone loaded biodegradable blend polymeric nanoparticles," Ciencia Rural, vol. 45, no. 11, pp. 2082-2088, 2015.

[10] S. Ueda, S. Matsumoto, A. Takagi, and T. Yamane, "Synthesis of poly(3-hydroxybutyrate-co-3-hydroxyvalerate) from methanol and n-amyl alcohol by the methylotrophic bacteria Paracoccus denitrificans and Methylobacterium extorquens," Applied and Environmental Microbiology, vol. 58, no. 11, pp. 3574-3579, 1992.

[11] H. F. Salem, "Sustained-release progesterone nanosuspension following intramuscular injection in ovariectomized rats," International Journal of Nanomedicine, vol. 5, no. 1, pp. 943-954, 2010.

[12] M. R. Guilherme, M. R. Mauricio, E. T. Tenório-Neto et al., "Polycaprolactone nanoparticles containing encapsulated progesterone prepared using a scCO2 emulsion drying technique," Materials Letters, vol. 124, pp. 197-200, 2014.

[13] J. F. S. F. Silva, P. Cnop, R. J. R. Sßnchez et al., "Avaliação da dinâmica útero-ovárica da égua sob o efeito de um implante 
subcutâneo de micro-cápsulas de polihidroxibutirato contendo progesterona," Rev. Port. Ciências Veterinárias, vol. 101, pp. 225230, 2006.

[14] J. M. Asua, "Miniemulsion polymerization," Progress in Polymer Science, vol. 27, no. 7, pp. 1283-1346, 2002.

[15] I. Rajot, S. Bône, C. Graillat, and T. Hamaide, "Nonionic nanoparticles by miniemulsion polymerization of vinyl acetate with oligocaprolactone macromonomer or miglyol as hydrophobe. application to the encapsulation of indomethacin," Macromolecules, vol. 36, no. 20, pp. 7484-7490, 2003.

[16] C.-Y. Huang, C.-M. Chen, and Y.-D. Lee, "Synthesis of high loading and encapsulation efficient paclitaxel-loaded poly(nbutyl cyanoacrylate) nanoparticles via miniemulsion," International Journal of Pharmaceutics, vol. 338, no. 1-2, pp. 267-275, 2007.

[17] T. S. Moreira, M. A. de Oliveira, L. M. da Rocha e Lima, M. N. de Souza, and J. C. da Silva Pinto, "Synthesis of nanoparticles loaded with tamoxifen by in situ miniemulsion RAFT polymerization," Macromolecular Symposia, vol. 344, no. 1, pp. 101-107, 2014.

[18] A. Guyot, K. Landfester, F. Joseph Schork, and C. Wang, "Hybrid polymer latexes," Progress in Polymer Science (Oxford), vol. 32, no. 12, pp. 1439-1461, 2007.

[19] E. Memisoglu-Bilensoy, M. Şen, and A. A. Hincal, "Effect of drug physicochemical properties on in vitro characteristics of amphiphilic cyclodextrin nanospheres and nanocapsules," Journal of Microencapsulation, vol. 23, no. 1, pp. 59-68, 2006.

[20] U. Bazylińska, A. Lewińska, Ł. Lamch, and K. A. Wilk, "Polymeric nanocapsules and nanospheres for encapsulation and long sustained release of hydrophobic cyanine-type photosensitizer," Colloids and Surfaces A: Physicochemical and Engineering Aspects, vol. 442, pp. 42-49, 2014.

[21] L. Cruz, L. U. Soares, T. D. Costa et al., "Diffusion and mathematical modeling of release profiles from nanocarriers," International Journal of Pharmaceutics, vol. 313, no. 1-2, pp. 198-205, 2006.

[22] F. J. Schork, Y. Luo, W. Smulders, J. P. Russum, A. Butté, and K. Fontenot, "Miniemulsion polymerization," Advances in Polymer Science, vol. 175, pp. 129-255, 2005.

[23] A. P. Romio, C. Sayer, P. H. H. Araújo, M. Al-Haydari, L. Wu, and S. R. P. Da Rocha, "Nanocapsules by miniemulsion polymerization with biodegradable surfactant and hydrophobe," Macromolecular Chemistry and Physics, vol. 210, no. 9, pp. 747751, 2009.

[24] F. R. Steinmacher, N. Bernardy, J. B. Moretto, E. I. Barcelos, P. H. H. Araújo, and C. Sayer, "Kinetics of MMA and VAc miniemulsion polymerizations using miglyol and castor oil as hydrophobe and liquid core," Chemical Engineering and Technology, vol. 33, no. 11, pp. 1877-1887, 2010.

[25] N. Bernardy, A. P. Romio, E. I. Barcelos et al., "Nanoencapsulation of quercetin via miniemulsion polymerization," Journal of Biomedical Nanotechnology, vol. 6, no. 2, pp. 181-186, 2010.

[26] P. E. Feuser, P. C. Gaspar, E. Ricci-Júnior et al., "Synthesis and characterization of poly(methyl methacrylate) pmma and evaluation of cytotoxicity for biomedical application," Macromolecular Symposia, vol. 343, no. 1, pp. 65-69, 2014.

[27] L. C. Becker, W. F. Bergfeld, D. V. Belsito et al., "Final Report of the cosmetic ingredient review expert panel safety assessment of polymethyl methacrylate (PMMA), methyl methacrylate crosspolymer, and methyl methacrylate/glycol dimethacrylate crosspolymer," International Journal of Toxicology, vol. 30, no. 3, 2011.
[28] U. M. Dhana lekshmi, G. Poovi, N. Kishore, and P. N. Reddy, "In vitro characterization and in vivo toxicity study of repaglinide loaded poly (methyl methacrylate) nanoparticles," International Journal of Pharmaceutics, vol. 396, no. 1-2, pp. 194-203, 2010.

[29] A. N. Mendes, I. Hubber, M. Siqueira et al., "Preparation and cytotoxicity of poly(methyl methacrylate) nanoparticles for drug encapsulation," Macromolecular Symposia, vol. 319, no. 1, pp. 34-40, 2012.

[30] V. Pucci, F. Bugamelli, R. Mandrioli, B. Luppi, and M. A. Raggi, "Determination of progesterone in commercial formulations and in non conventional micellar systems," Journal of Pharmaceutical and Biomedical Analysis, vol. 30, no. 5, pp. 1549-1559, 2003.

[31] R. M. T. Fernandes, G. C. Gomes, A. M. Porcari et al., "LC-MS/ MS quantitation of plasma progesterone in cattle," Theriogenology, vol. 76, no. 7, pp. 1266-e2, 2011.

[32] G. R. Pereira, J. M. Marchetti, and M. V. L. B. Bentley, "A rapid method for determination of progesterone by reversed-phase liquid chromatography from aqueous media," Analytical Letters, vol. 33, no. 5, pp. 881-889, 2000.

[33] H. M. Leith, P. L. Truran, and S. J. Gaskell, "Quantification of progesterone in human saliva," Biological Mass Spectrometry, vol. 13, no. 5, pp. 257-261, 1986.

[34] P. Liere, Y. Akwa, S. Weill-Engerer et al., "Validation of an analytical procedure to measure trace amounts of neurosteroids in brain tissue by gas chromatography-mass spectrometry," Journal of Chromatography B: Biomedical Sciences and Applications, vol. 739, no. 2, pp. 301-312, 2000.

[35] T. Lukkainen, W. Vandenheuvel, and E. Horning, "An estrogen determination method using gas chromatography," Biochimica et Biophysica Acta, vol. 62, no. 1, pp. 153-159, 1962.

[36] H.-I. Chang, M. R. Williamson, Y. Perrie, and A. G. A. Coombes, "Precipitation casting of drug-loaded microporous PCL matrices: Incorporation of progesterone by co-dissolution," Journal of Controlled Release, vol. 106, no. 3, pp. 263-272, 2005.

[37] G. V. Salmoria, P. Klauss, K. M. Zepon, and L. A. Kanis, "The effects of laser energy density and particle size in the selective laser sintering of polycaprolactone/progesterone specimens: morphology and drug release," International Journal of Advanced Manufacturing Technology, vol. 66, no. 5-8, pp. 11131118, 2013.

[38] D. Maliwal, P. Jain, A. Jain, and V. Patidar, "Determination of progesterone in capsules by high-performance liquid chromatography and UV- spectrophotometry," Journal of Young Pharmacists, vol. 1, no. 4, p. 371, 2009.

[39] Z. Wu, C. Zhang, C. Yang, X. Zhang, and E. Wu, "Simultaneous quantitative determination of norgestrel and progesterone in human serum by high-performance liquid chromatographytandem mass spectrometry with atmospheric pressure chemical ionization," Analyst, vol. 125, no. 12, pp. 2201-2206, 2000.

[40] ICH, "ICH Topic Q2 (R1) validation of analytical procedures: text and methodology," in Proceedings of the international conference on harmonisation of technical requirements for registration of pharmaceuticals for human use, 2005, http://www.ich .org/fileadmin/Public_Web_Site/ICH_Products/Guidelines/Quality/Q2_R1/Step4/Q2_R1__Guideline.pdf.doi.

[41] F. Tiarks, K. Landfester, and M. Antonietti, "Preparation of polymeric nanocapsules by miniemulsion polymerization," Langmuir, vol. 17, no. 3, pp. 908-918, 2001.

[42] United State Pharmacopoeia, Validation of Compendial Procedures, United States Pharmacopoeia XXXVII Natl. Formul. XXXII. (2014) 1-5. 
[43] A. P. Romio, N. Bernardy, E. Lemos Senna, P. H. H. Araújo, and C. Sayer, "Polymeric nanocapsules via miniemulsion polymerization using redox initiation," Materials Science and Engineering C, vol. 29, no. 2, pp. 514-518, 2009.

[44] P. E. Feuser, P. C. Gaspar, A. V. Jacques et al., "Synthesis of ZnPc loaded poly(methyl methacrylate) nanoparticles via miniemulsion polymerization for photodynamic therapy in leukemic cells," Materials Science and Engineering C, vol. 60, pp. 458-466, 2016. 

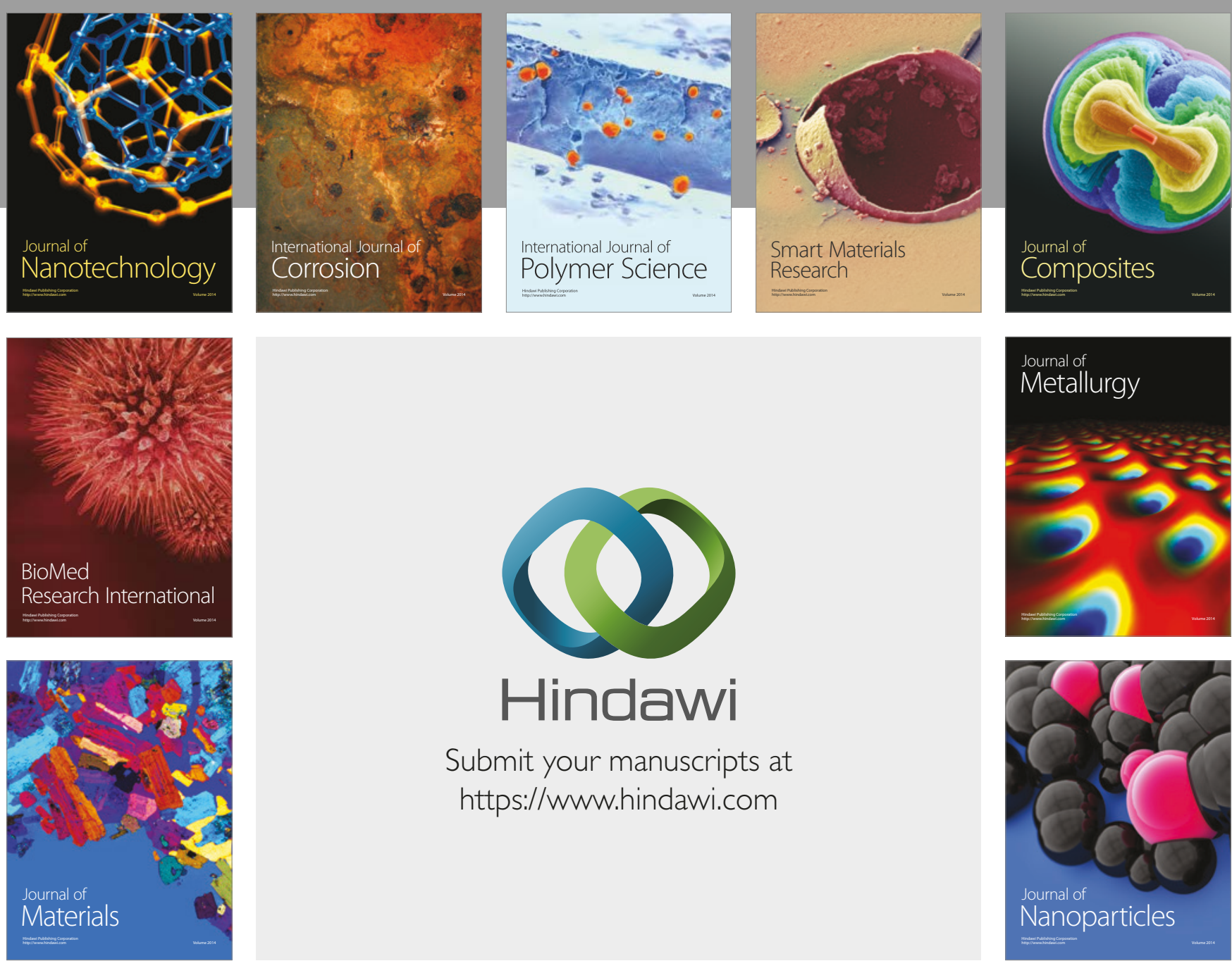

\section{Hindawi}

Submit your manuscripts at

https://www.hindawi.com
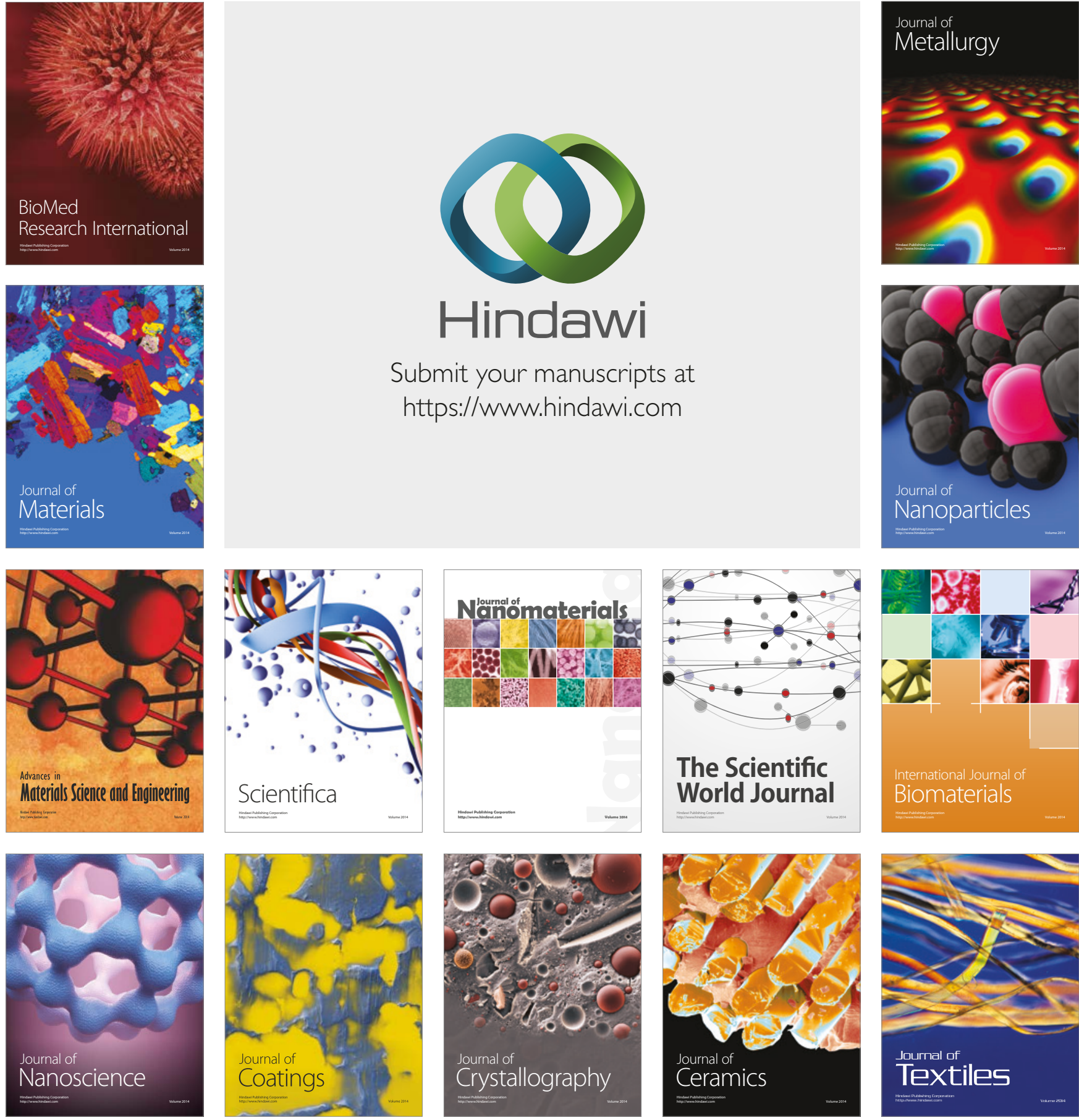

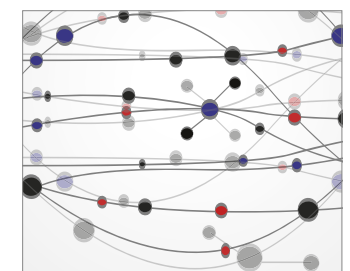

The Scientific World Journal
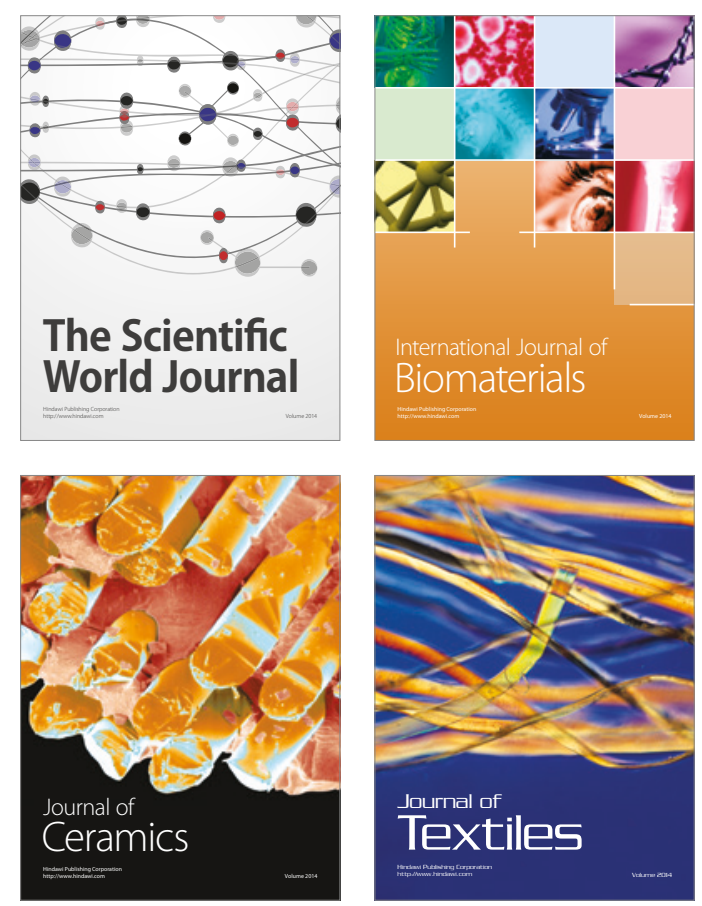